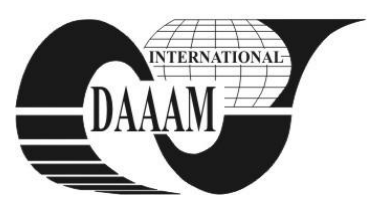

\title{
ANALYSIS OF ACOUSTICAL PROPERTIES OF MONO AND MULTILAYER SOUND ABSORBERS
}

\author{
BILOVA, M[onika]; LUMNITZER, E[rvin]; BADIDA, M[iroslav] \& KRALIKOVA, R[uzena]
}

\begin{abstract}
Sound-absorbing materials are utilized in almost all areas of noise control engineering. This paper deals with the acoustical parameters of mono and multilayer sound absorbers and shows the possibilities of their improvement by their appropriate combinations. Acoustic parameters of five samples were tested in impedance tube and the results were compared. The main goal of the performed measurements was to find out how thickness of monolayer absorbers affects their soundabsorbing qualities and how is possible to improve sound-absorbtion by multiplaying the absorptive layers.
\end{abstract}

Key words: sound absorption coefficient, impedance tube, sound absorber

\section{INTRODUCTION}

Design of sound absorbers that provide sufficient sound absorption coefficient that minimizes the size and cost, does not introduce any environmental hazards, and stands up to hostile environments is one of the most frequent problems faced by noise control engineers. Material used for sound absorption may be fibruous, cellular or granular. It is important to know their acoustical properties. Very high sound absorption coefficient can be achived by using a number of sound absorbing layers of different materials.

\section{SOUND ABSORPTION COEFFICIENT}

A material's sound absorbing properties can be described as a sound absorption coefficient in a particular frequency range. The sound absorption coefficient $\alpha$ is defined as the ratio of the sound power, $W_{n r}$, that is not reflected and the sound power incident on the face of the absorber, $W_{i n c}$ :

$$
\alpha=\frac{W_{n r}}{W_{i n c}}
$$

The coefficient can be viewed as a percentage of sound being absorbed, where 1.00 is complete absorption (100\%) and 0.01 is minimal (1\%). For convenience in analyses, the absorption coefficient is defined in terms of sound pressure reflection factor $R$ of the absorber interface, namely

$$
\alpha=1-|R|^{2}
$$

The reflection factor $R$ is a function of the angle of sound incidence, the frequency, the material and the geometry of the absorber. (Vér \& Beranek, 2006)

\subsection{The critical features to the optimation of absorption performance \\ A number of features will significantly impact the absorption performance. They can also be categorised as being part of the intrinsic material properties or being defined as part or consequence of the conditions under which the sound absorbing system is processed. These features are the}

followings: total thickness and surface, presence of membrane, presence of layers, including skin. (Skinner et al., 2006)

The impact of these features on the performance of a system to absorb sound can be described in a simple schematic manner noting that in reality it is actually impossible to separate the impact of effects as they are linked (see Fig. 1.). Summarising the effects highlighted in the graphs increasing density / thickness / porosity and airflow will result in increased levels of absorption performance. (Skinner et al., 2006)

\subsection{Impedance tube method quantifying the sound absorbing behavior}

Although a number of measurement techniques can be used to quantify the sound absorbing behavior, most often the determination of the properties takes place in a standing wave tube. This is because in a tube the mathematic problem becomes one-dimensional (in a certain bandwidth): sound waves can only propagate in one direction. This makes the experimental set-up relatively simple and small. In Fig. 2. a sketch of a basic technique is shown. (Bree, 2008)

In (Chung \& Blazer, 1980) presented a technique which is based on the transfer function of two fixed microphones which are located at two different positions in the tube wall. The standing wave pattern is built up from a broadband stationary noise signal. With the measured transfer function, incident and reflected waves are separated mathematically. This leads to the reflection coefficient of the sample for the same frequency band as the broadband signal. The impedance and absorption coefficient can be derived as well. The method is accurate and considerably fast. (Bree, 2008)

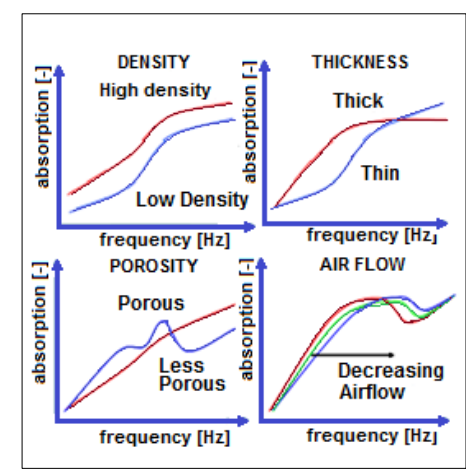

Fig. 1. Schematics of the key features driving absorption performance (Skinner et al., 2006)

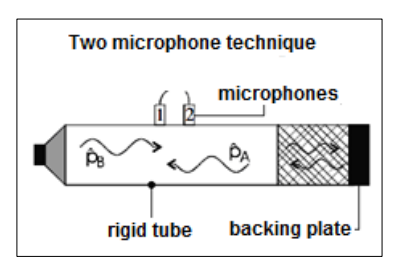

Fig. 2. Schematic representations of a measurement technique in an impedance tube (Bree, 2008) 


\section{RESULTS OF IMPEDANCE TUBE MEASUREMENT OF MONO AND MULTILAYER ABSORBERS}

According to the two microphone technique several measurements of samples of different material and thickness were carried out. The samples prepared for measurements are shown in Fig. 3. The results of these measurements are shown in figures 4. -8 .

Fig.4. shows that the limp plastic plate has poor absorptive properties. The maximal sound absorption coeffiecient $\alpha=$ 0.25 was achieved at frequency $f=5000 \mathrm{~Hz}$. Fig. 5. and Fig. 6 . show the absorptive properties of material called ekomolitan of different thicknesses $[(t=20 \mathrm{~mm})$ and $(t=50 \mathrm{~mm})]$. These measurements proved that with increasing thickness the sound absorption coefficient is improved mainly at frequency range $f=500 \mathrm{~Hz}$ to $f=2500 \mathrm{~Hz}$. On the other hand at frequency $f=3000 \mathrm{~Hz}$ the sound absorption coefficient is higher for the thinner material. In Fig. 7. and Fig. 8. the acoustical properties of multilayer sound absorbers are shown. These measurements proved that by multiplaying the absorptive layers and by proper combination of materials good results can be achieved at higher freuquencies.

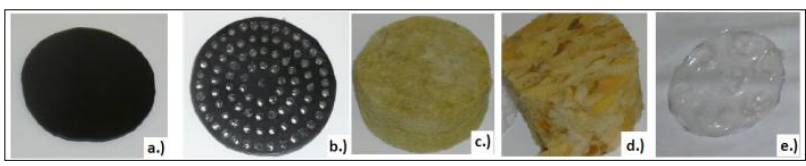

Fig. 3. Measured samples: a.) limp plastic plate, b.) perforated limp plastic plate, c.) nobasil, d.) ekomolitan, e.) foil

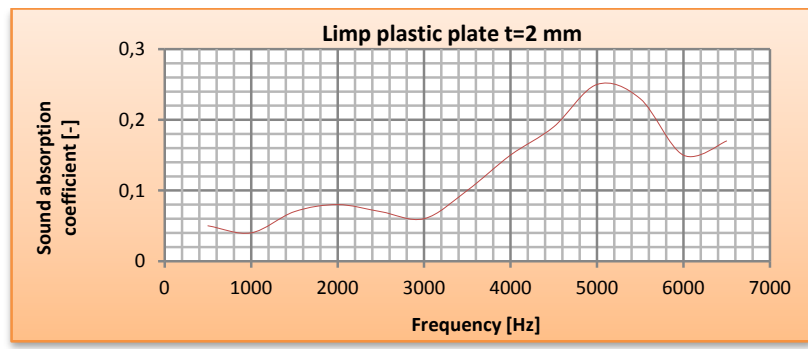

Fig. 4. Limp plastic plate $(t=2 \mathrm{~mm})$, frequency range from 100 $\mathrm{Hz}$ to $6300 \mathrm{~Hz}$

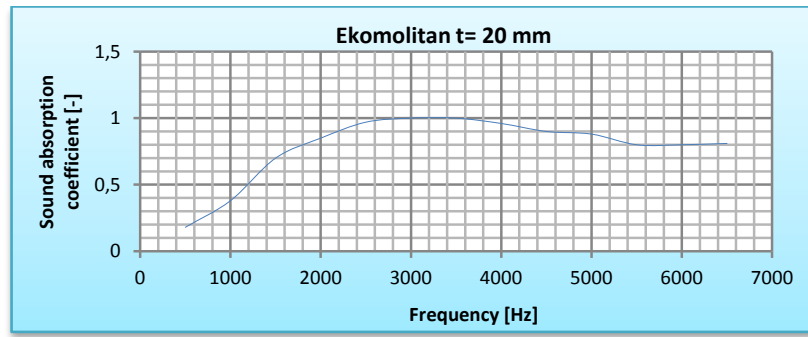

Fig. 5. Ekomolitan $(t=20 \mathrm{~mm})$, frequency range from $100 \mathrm{~Hz}$ to $6300 \mathrm{~Hz}$

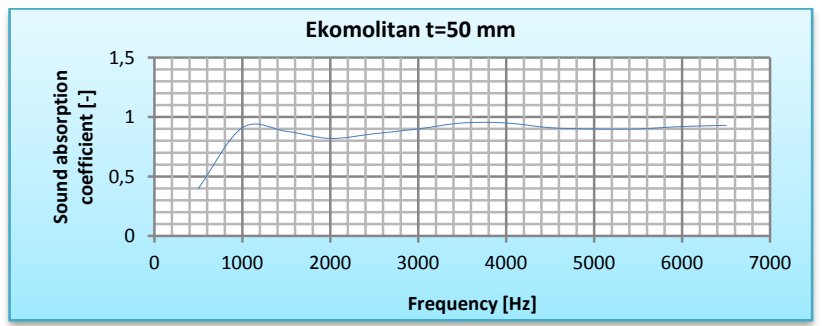

Fig. 6. Ekomolitan $(50 \mathrm{~mm})$, frequency range from $100 \mathrm{~Hz}$ to $6300 \mathrm{~Hz}$

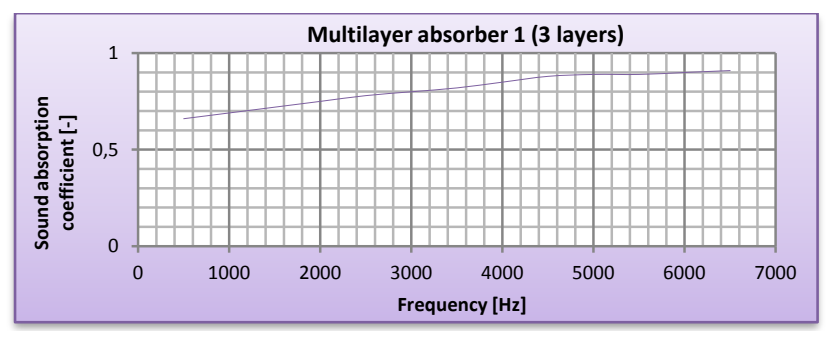

Fig. 7. Multilayer absorber 1: nobasil $(30 \mathrm{~mm})$ - ekomolitan $(50 \mathrm{~mm})$ - foil, frequency range from $100 \mathrm{~Hz}$ to $6300 \mathrm{~Hz}$

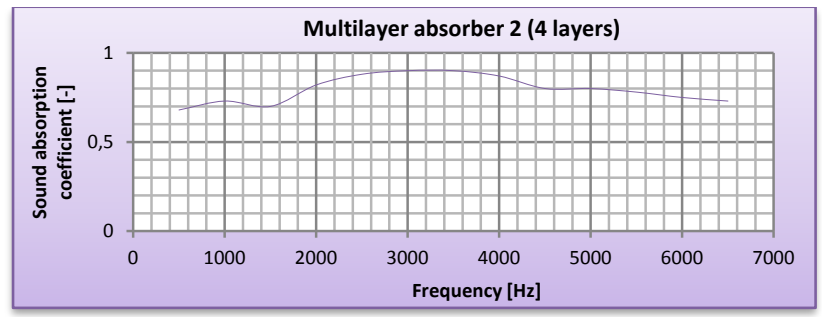

Fig. 8. Mulitlayer absorber 2: perforated limp plastic plate (2 $\mathrm{mm})$, nobasil $(30 \mathrm{~mm})$ - ekomolitan $(50 \mathrm{~mm})$ - foil, frequency range from $100 \mathrm{~Hz}$ to $6300 \mathrm{~Hz}$

\section{CONCLUSION}

The performed measurements proved the followings:

- The monolayer absorber "ekomolitan" $\mathrm{t}=20 \mathrm{~mm}$ has excellent absorptive properties at higher frequency range $f>3000 \mathrm{~Hz}$.

- The monolayer absorber "ekomolitan" $\mathrm{t}=50 \mathrm{~mm}$ has better absorptive features at lower frequencies.

- Multylayer absorbers enable gainig steady absorption coefficient in a relatively wide frequency range.

Results obtained with multilayer absorbers are somewhat better than those obtained with certain monolayer absorbers. However, the improvements seldom justify the added cost and complexity.

\section{ACKNOWLEDGEMENTS}

This paper was supported by project KEGA 3/7426/09.

\section{REFERENCES}

Badida, M.; Lumnitzer, E. \& Románová, M.(2005): Analyses of sound isolating attributes for materials from the recyklation of vehicles, Trans \& MOTOAUTO' 05+: Proceedings: 12. international scientific - technical conference, 23-25 November 2005, Veliko Tarnovo. pp. 95-96. ISBN 954-9322-09-2, S-TU of Mechanical engineering of Bulgaria, Sofia

Bree, H.E.(2008). The Microflown. e-book. Chapter 6: Impedance. Available from:

www.microflown.com/library/presentation/presentation.ht ml Accessed: 2011-05-03

Chung, J.Y. \& Blaser, D.A. (1980). Transfer function method of measuring in-duct acoustic properties. I. Theory, Journal of the Acoustical Society of America, 68(3), (907-913), ISSN 0001-4966

Skinner, Ch.; Peters, J. \& Vandenbroeck, J. (2006). Acoustic Absorbers: A third way for the management of sound in automobiles Available from:

www.huntsman.com/pu/media/utech2006_acoustic_materia ls.pdf Accessed: 2011-05-03

Vér, I.L. \& Beranek, L.L. (2006). Noise end vibration control engineering: principles and applications. John Wiley \&Sons Inc., Hoboken, New Jersey ISBN-13 978-0-47144942-3, USA 